\title{
Dynamic Electricity Pricing - Modeling Manufacturer Response and an Application to Cement Processing
}

\author{
Derya Eryilmaz ${ }^{1}$ Jeffrey Apland ${ }^{2} \&$ Timothy M. Smith ${ }^{3}$ \\ ${ }^{1}$ Ph.D., Charles River Associates, Boston MA, United States \\ ${ }^{2}$ Ph.D., Department of Applied Economics, University of Minnesota, Twin Cities MN, United States \\ ${ }^{3}$ Ph.D., Department of Bioproducts and Biosystems Engineering, University of Minnesota, Twin Cities MN, \\ United States
}

Correspondence: Derya Eryilmaz, Ph.D. Charles River Associates, Boston MA, United States. Tel: 1-617-425-3080. E-mail: deryilmaz@crai.com or ery.derya@gmail.com

Received: June 3, 2019

Accepted: July 7, 2019

Online Published: July 31, 2019

doi:10.5539/eer.v9n2p1

URL: https://doi.org/10.5539/eer.v9n2p1

\begin{abstract}
Dynamic pricing, also known as real-time pricing, provides electricity users with an economic incentive to adjust electricity use based on changing market conditions. This paper studies the economic implications of real-time pricing mechanisms in a cement manufacturing plant. Production for a representative cement manufacturing plant is modeled using stochastic mathematical programming. The results show that a cement plant can a) reduce electricity costs by shifting electricity load of certain processes to times when electricity prices are lower, and $b$ ) profitably reduce electricity use during peak prices through more efficient scheduling of production under real-time pricing compared to fixed pricing. The results suggest that building scheduling flexibility into certain industrial manufacturing processes to reschedule electricity consumption when the electricity prices at their peak may be economical. The results also suggest that shifts in the production schedule of a cement manufacturer that result from real-time pricing may also influence environmental impacts. The modelling framework modeled real-time pricing as a source of risk in this study, which is also applicable to other energy intensive industries. As such, dynamic pricing strategies that include the non-market impacts of electricity generation should be further explored.
\end{abstract}

Keywords: energy management, linear programming, dynamic electricity pricing, emissions

\section{Introduction}

The growth of electricity demand has slowed in the past decade and it is projected to continue slowing through 2040 in the United States (EIA, 2014). One of the major reasons for the decline in growth has been the substantial increase in investments that enhance energy efficiency and load management, particularly in the industrial sector. Rapidly declining costs of renewable energy resources such as distributed solar also contributed to slow electricity demand (US DOE, 2015). Approximately one-third of the total US electricity production is used by the industrial sector (EIA, 2013; Gielen \& Taylor, 2007). Further, of total industrial energy consumption in the United States, about $48 \%$ is electricity (US EIA, 2015). For instance, electricity makes up approximately 25\% of the energy used in cement production (Kramer et al., 2009; Madlool et al., 2011; Madlool, 2013). Considering the substantial amount of electricity demand in such industries, efficient use of electricity becomes an important part of production planning and a potential driver of market behavior.

Dynamic pricing, also known as real-time pricing, is one useful method for managing electricity consumption since it provides customers with an economic incentive to adjust electricity use based on changing market conditions. Although there have been initiatives for implementing more time-varying retail rates (Taylor, 2002; Chao, 2009; Bharvirkar et al., 2008; Faruqui et al., 2010; Alcott, 2011; Cooke, 2011), the majority of retail industrial customers face retail rates that are fixed regardless of the level of demand. Alternatively, larger industrial customers may negotiate time-of-use rate contracts under which the electricity rate is higher when electricity demand is typically high, and lower when demand is, on average, low. Flat, or minimally varying, rates do not give consumers a direct incentive to adjust their electricity consumption in response to actual changes in the cost of generation. Further, consumers may end up paying higher prices when the real-time 
electricity prices are lower during off-peak hours in the wholesale market (Faruqui et al., 2010). Real-time pricing provides electricity customers with an opportunity to use more electricity at the times when the price of electricity is justified by the economic activity it is supporting, which in the aggregate can also reduce consumer bills and can eventually shave costly peak loads facing utilities. Significant amounts of electricity savings are possible through upgrading technology and machinery to improve efficiencies, but dynamic pricing offers a low cost way to manage electricity use (Olsen et al., 2010) by shifting it away from peak-load times (Wang \& $\mathrm{Li}$, 2015; Changhui et al., 2017; DOE, 2006).

Adjusting to real-time pricing can be difficult for large industrial consumers, especially for firms that do not have a flexible electricity consumption schedule (Eryilmaz et al., 2016; Olsen et al., 2010). Thus, the economic implications of real-time pricing may vary by industry and production technology. This study focuses on the implications of real-time electricity pricing on cement production planning. Cement manufacturing is considered to be a suitable industry to implement real-time pricing since it has been estimated that up to $50 \%$ curtailment of electricity use is possible through dynamic pricing (Olsen et al., 2010). While management of electricity consumption is possible in this energy-intensive industry, it has mostly been implemented through interruptible tariffs, under which electricity users agree to curtail a certain amount of electricity usage through a pre-determined agreement with the utility. Dynamic pricing is typically thought to be an "electricity usage shifting" mechanism in which the timing of electricity use changes (Wang \& $\mathrm{Li}, 2015$ ). Under real-time pricing, customers may choose to adjust electricity consumption on an hourly basis, which requires additional flexibility in the operational schedule of the implementing facility (Borenstein, 2005). In addition to the customer-level benefits, demand response in large industrial sectors benefit the electric system as a whole (Khan et al., 2016; Eid et al., 2016). More broadly, real-time pricing is found to be an efficient tool in competitive markets and the benefits of real-time pricing have been observed in other energy and utility systems (Hailong et al., 2015). Further, a study by Bornstein (2005) emphasizes that real-time pricing is a superior option, particularly for large industrial customers compared to time-of-use pricing in terms of electricity cost-efficiencies and rescheduling production (Borenstein, 2005). For example, plants may shut down or interrupt electricity use during the times when the electricity price is at peak by having the capability of over-producing and storing work-in-progress inventory or switching to an alternative fuel. A number of studies have attempted to quantify the energy and economic savings of real-time pricing in manufacturing, including cement. An early white paper by Zarnikau (1997) outlines the economic benefits of real-time pricing for manufacturing including customer bill savings. Hamdani (2000) found approximately $\$ 1$ million/year in energy cost savings due to scheduling energy consumption for certain part of cement processes with real-time pricing. Another study found 9MW of peak load reduction per year with real-time pricing in cement operations in South Africa (Mathews et al., 2007). Finally, an empirical study examining the challenges and benefits of dynamic pricing on load forecasting and utility resource planning, concluded that dynamic pricing can be an efficient pricing scheme, benefiting both the customer and the utility (Khan et al., 2016).

The primary goal of this study is to provide an understanding of economic implications of real-time pricing mechanisms in a large energy-using industrial setting. This paper presents a production model for a representative cement manufacturing plant including energy-intensive flow and batch processes (e.g. raw milling, kiln, finish grinding). A mathematical programming model is developed to study alternative electricity demand scenarios in the context of the overall economic choices for the facility. The analysis specifically considers the Midcontinent Independent System Operator (MISO) territory market conditions and operational factors, as well as characteristics of cement manufacturing in the Midwest region. A multi-period stochastic programming framework is used to capture the sequential nature of the production processes, the use and availability of processing equipment, and the stochastic and real-time nature of electricity prices. The objectives of this research are to show a) how energy management under real-time pricing can influence operating profit of a cement manufacturing plant, b) how electricity consumption might change in response to real-time pricing, and c) how this change in electricity consumption alters the facility's $\mathrm{CO}_{2}$ profile operating in the MISO territory.

This paper makes several contributions to the discussion of the economics of real-time pricing. The modeling framework is designed to analyze the adoption of real-time pricing by large manufacturing plants, including assessments of the relative efficiency of energy use and curtailment of electricity consumption in various stages of production as real-time electricity prices change. Numerous researchers have employed empirical methods to analyze the behavioral impact of dynamic pricing. However, analytical approaches incorporating large demand shifting potential have been limited (Rosenthal, 2017; Lijesen, 2007), particularly because of the limited knowledge of customers' varying electricity use. This study addresses this limitation within a specific setting of an energy intensive industrial customer. More specifically, the analysis provides useful production process 
management information to cement manufacturing plants regarding the impacts of real-time pricing and its implications for profitability. The model developed in this study demonstrates an analysis of strategic and operational practices involving production capacity decisions, production scheduling and finally management of electricity consumption during production under real-time electricity pricing.

Following the background section, the paper is organized as follows: an analytical framework section provides an in-depth explanation of the modeling assumptions and model framework, and is followed by details of the analysis and data. The results section includes the explanation of the optimal production plans for three electricity markets and various market conditions. Following an interpretation of the results, some possible directions for future research are discussed.

\section{Background}

\subsection{Cement Industry and Energy Management}

The cement industry was selected for an analysis of real-time pricing for several reasons. First, it is one of the highest energy and emissions intensive manufacturing industries in the U.S. because the production processes use large quantities of fossil fuels (Hanle, 2004). Approximately 50\% of the production cost comes from energy inputs such as coal, natural gas and electricity (KEMA, 2005). As opposed to the other fuels, electricity consumption is more flexible in a cement production process. Thus, allowing cement plants to track real-time prices and curtail electricity use when electricity price is high may have significant economic and energy efficiency impacts.

Second, while the market price of cement has been increasing, cement production has slowed in the past few years (Van Oss, 2014). One of the major reasons for slower cement production is recent environmental regulations, particularly the 2010 National Emissions Standards for Hazardous Air Pollutants (NESHAP) protocol for cement plants. Cost pressures stemming from regulation has also encouraged research on energy efficiency in cement plants and opportunities for clean ways of manufacturing cement in the United States (Van Oss, 2014).

Finally, cement plants typically operate 24 hours-a-day. Their use of electricity, compared to the other fuels, is highly interruptible during several stages of the operation where electricity is used intensively and often when the electricity price is high (Olsen et al., 2010). Thus, this study posits that it is possible for cement producers to profitably respond to real-time pricing by altering the scheduling of these processes.

\subsection{Cement Production Process}

Cement production includes three major production processes: raw milling, kiln and finish grinding (or cement milling). Cement production is mostly a flow process with finish grinding a batch process. Initially, all raw materials are brought to a raw milling process, which can be a wet or dry process. With the wet process, water is used for grinding raw materials and the grinding is less energy-intensive than dry raw milling, where no water is being used. Thus, we assume a wet processing method in this analysis. The intermediate product of raw milling is raw mix. In the second stage, the raw mix is burned during the kiln process, which typically uses a mix of different energy sources including coal, electricity natural gas and oil. The kiln is the most energy and emissions intensive production activity in the entire cement production cycle. The intermediate product of the kiln is called kiln feed, which is directly transferred into the finish grinding coolers -- all of electricity in this production activity is used to move the kiln feed to the coolers. The hot clinker is cooled clinker coolers, which moves the combustion air towards the hot clinker (IEA, 2010), and the air is moved with the help of large fans, which are the primary electricity consumers in this stage. The final stage of production is the finish grinding, the most electricity intensive stage of the production cycle after kiln, where electricity is used to grind clinker, the cooled kiln feed, to produce cement (Olsen et al., 2010; IEA, 2010). Cement manufacturing is cyclical (Olsen et al., 2010), and production operations may shut down due to lower market demand for cement or if maintenance is required. Storage of intermediate products is possible, between the kiln and finish grinding processes and finally, after the finish grinding process to store the final product.

To demonstrate the stochastic, multi-period mathematical programming approach, the model is constructed to allow for a delay (i.e., reduction of production) in the finish grinding process to manage electricity consumption a process that uses a significant proportion of the facility's electricity consumption. Later, other potential management decisions to manage electricity use, including scheduling and input substitution, will be discussed within the framework of the model. Finally, transportation costs can become significant component of costs - for example, cement plants are usually located close to the raw material supplies to minimize transportation costs. Therefore, the model assumes constant transportation costs in this analysis. Figure 1 illustrates one-cycle of 
cement production with the associated input requirement coefficients to produce one ton of cement.

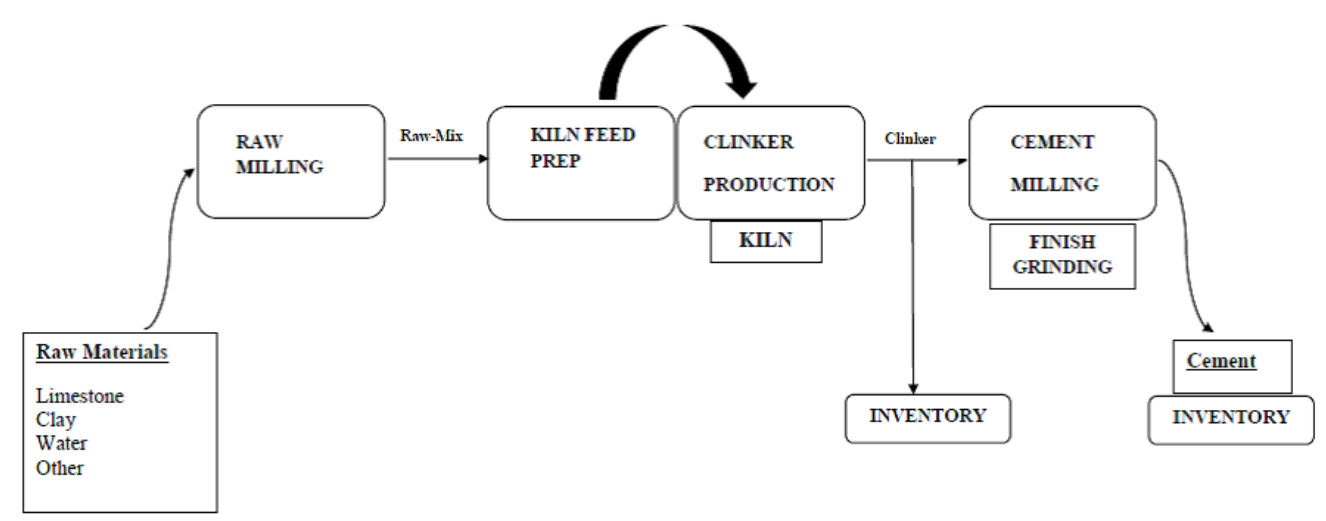

Figure 1. Cement production process

Note. This figure illustrates the cement production and disaggregates different production activities.

Approximately $30 \%$ to $40 \%$ of total energy use in cement production comes from coal. The remaining energy sources are: electricity (11\%-25\%), natural gas (7\% to $30 \%)$, petroleum coke (13\%) and fuel oil (35\%) (Madlool et al., 2011; Madlool et al., 2013 (Note 1)). Electricity and natural gas is consumed during almost all of the production processes, while petroleum coke is mostly used as an alternative type of fuel during the kiln activity. The overall cement production process is highly automated. All raw materials are used - there are no by-products during the production process, except clinker dust, which is cleared with vacuums in the end of the production and is not reused during production.

All of the cement production processes described above are included in the multi-period mathematical programming model of a representative cement plant. The model includes discrete, thirty minute long production periods over a three month long (i.e., seasonal) planning horizon. The model assumes that the real-time electricity price fluctuations in a day are observable by the plant, and so it is possible to manage electricity use in a production cycle responding to price fluctuations through the scheduling of finish grinding. Real-time pricing signals are observed by the plant every thirty minutes. The plant is a price-taker, which means that changes in the electricity consumption of the plant do not influence the prices of electricity. (Note 2) Further details on the model parameters are presented in Section 4.1, 4.2 and Appendix Table 1.

\subsection{Wholesale Electricity Markets}

The wholesale electricity market includes buyers and sellers of power between generators and resellers. Regional Transmission Organizations (RTOs) and Independent System Operators (ISOs), such as MISO, operate wholesale electricity markets and set the clearing price for electricity. The process includes matching electricity supply to demand at various pricing nodes across the ISO territory. Generators bid based on how much supply is available and MISO sorts thee bids from lowest to highest and dispatch at the relevant hour. The market clearing price is based on the marginal unit of generation required to meet demand.

MISO determines electricity prices primarily through two markets: real-time market and day-ahead market. Real-time market is a spot market, which balances real-time supply and demand in the MISO market. Day-ahead market is a forward market, which reflects participants' expectations for the next day. (Note 3) MISO uses Security Constrained Economic Dispatch - SCED model for its real-time and future operations (i.e., a continuous process for balancing the least cost demand and supply while recognizing current or future operating conditions in the market, see Note 4). MISO uses load forecasts and generator offers to balance the market instantaneously.

We use real-time electricity prices to develop the cement producer's problem under the assumption that the cement producer instantly receives the clearing price of electricity in the MISO market. (i.e., large industrial customer is a bidder in the real-time market). Large industrial electricity customers are still not fully equipped to track real-time electricity prices. This study aims to demonstrate the energy management implications if a cement producer paid known, real-time electricity prices based on MISO market data. Doing so focuses the discussion on ways electricity use could be managed in response to real-time price. We follow this with a discussion of the nature of electricity price risk and possible modeling approaches for firms using electricity and facing input price risk from real-time pricing. 


\section{Method}

\subsection{A Mixed Integer Programming Model of Cement Production}

A mathematical programming model of cement plant operation is developed to study alternative demand reduction policies in the context of the overall economic choices of cement producers. Firm-level mathematical programming models are widely used to study the impacts on producers of changing market conditions, technology and public policies (Mendez-Pinero \& Colon-Vazquez, 2016; Hillier, 2012; McCarl \& Spreen, 2013; Rosenthal, 2017). A multi-period framework is used here to capture the sequential nature of the production processes, the use and availability of processing equipment, and the stochastic nature of energy prices characteristics that are central to cement production and the electricity demand reduction problem. Integer, process-scheduling variables are used to capture discrete choices involving shutting down or altering production processes in order to manage energy use in the context of prevailing electricity pricing policies. A general algebraic statement of the model follows:

Maximize:

$$
Z=-\sum_{h \in \theta_{Z M}} \sum_{t \in \theta_{T}} R M_{h t} Z M_{h t}-\sum_{h \in \theta_{Z N}} R N_{h} Z N_{h}+\sum_{g \in \theta_{Y M}} \sum_{t \in \theta_{T}} P M_{g t} Y M_{g t}+\sum_{g \in \theta_{Y N}} P N_{g} Y N_{g}
$$

Subject to:

$$
\begin{gathered}
\sum_{i \in \theta_{X}} \sum_{j \in \theta_{X M}} \sum_{t_{I} \in \theta_{T X}} A Z M_{i j h t_{t}} X P_{i j t_{I}}+\sum_{i \in \theta_{X}} \sum_{k \in \theta_{X S}} \sum_{t_{I} \in \theta_{T X}} A Z S_{i k h t_{t}} X S_{i k t_{I}}-Z M_{h t}=0 ; \quad h \in \theta_{Z M} t \in \theta_{T} \\
\sum_{i \in \theta_{X}} \sum_{j \in \theta_{X M}} \sum_{t_{I} \in \theta_{T X}} A Z N_{i j h t_{I}} X P_{i j t_{I}}-Z N_{h}=0 ; \quad h \in \theta_{Z N} \\
-\sum_{i \in \theta_{X}} \sum_{j \in \theta_{X M}} \sum_{t_{I} \in \theta_{T X}} A Y M_{i j g t_{t}} X P_{i j t_{I}}+Y I_{g t}-Y I_{g(t-1)}+Y M_{g t}=0 ; g \in \theta_{Y M} \quad t \in \theta_{T} \\
-\sum_{i \in \theta_{X}} \sum_{j \in \theta_{X M}} \sum_{t_{I} \in \theta_{T X}} A Y N_{i j g t_{I}} X P_{i j t_{I}}-Y N_{g}=0 ; \quad g \in \theta_{Y M} \\
X P, X S, Y I, Z M, Z N \geq 0 ; \\
Z M \leq Z M_{\text {max }} ; Z N \leq Z N_{\max } ; Z M \geq Y M_{\min } ; \quad Y N \geq Y N_{\text {min }} ; \quad Y I \leq Y I_{\text {max }} ;
\end{gathered}
$$

XS Integer

where the sets are defined as $\theta_{\mathrm{X}}$ Production Activities; $\theta_{\mathrm{M}}$ Production Methods; $\theta_{\mathrm{T}}$ Time Periods; $\theta_{\mathrm{ZM}}$ Multi-Period Inputs; $\theta_{\mathrm{ZN}}$ Non-Multi-Period Inputs; $\theta_{\mathrm{YM}}$ Multi-Period Products; $\theta_{\mathrm{YN}}$ Non-Multi-Period Products; $\theta_{\mathrm{XM}}$ Methods mapped to Production Activities; $\theta_{\mathrm{TX}}$ Production Activities mapped to Initial Processing Periods; $\mathrm{XP}_{\mathrm{ijt}_{\mathrm{I}}}$ is the level of production process activity $\mathrm{i}$, using method $\mathrm{j}$, and beginning in time period $\mathrm{t}_{\mathrm{I}}$.

By including alternative process methods, the model can allow for alternative input combinations for a particular process including alternative energy sources (e.g., distributed on-site generation) or combinations of raw materials. The alternative methods can also be used to capture the various fees and prices associated with a demand reduction policy. (Note 5) Each process can take place over several production periods with multi-period input requirements indicated by matrix AZM and non-multi-period input requirements given by AZN. Integer variable $\mathrm{XS}_{\mathrm{ikt}_{\mathrm{I}}}$ is used to capture discrete process scheduling decisions (i.e., this variable is operating as an on and off switch for the cement operations). For example, using available processing equipment and making production capacity available for use by processing activities, XP. The transfer of equipment resources to processing capacity is accomplished with coefficients matrix AZS. Inputs and products may be multi-period, if supply and demand conditions vary by production period, or classified as non-multi-period to manage model size when the time period of availability, use or production is not critical. Input use or purchase variables are ZM and $\mathrm{ZN}$ for multi-period and non-multi-period inputs, respectively. Output or product sales are represented by variables YM (multi-period) and YN (non-multi-period). Quantity restrictions on input use or product demand are captured through upper and lower bounds (constraints are defined in (6)). Using input price parameters RM and $\mathrm{RN}$ and product price parameters PM and PN, the objective function (1) is total net revenue. The objective function is to maximize net revenue from production. Ending inventory variables YI capture the storage of products, with storage capacity indicated by upper bounds $\mathrm{YI}_{\max }$ (equation (6). The inventory variables can account for the storage of final products for later sale or the storage of intermediate products between processes. The latter is an important feature for modeling the disruption of a process to reduce electricity use.

Parameters AZM and AZN are matrices of net resource requirements per unit of production activities XP, and AZS are per unit net resource requirements for scheduling variables XS. Input constraints (2) and (3), then, balance net input use by production activities plus net use by scheduling activities (multi-period inputs only) 
with input purchases or fixed resource availability. Per unit product yields for production activities are matrices AYM (multi-period) and AYN (non-multi-period). For multi-period products, inventory from the previous period plus production during the period must balance with product sales plus ending inventory by constraints (4). For non-multi-period products, equation (5) balances production and sales.

The operations model described above is used in a stochastic programming analysis of energy management. Discrete stochastic programming (DSP, sometimes called stochastic programming with recourse), is well suited to the analysis because we allow the plant to observe real-time prices of electricity and have the option to shut down operation for every thirty minute at finish grinding stage of production. (Note 6) A two stage decision process is assumed. In stage one, processing and cement storage capacity decisions are made. Also, any agreements on electricity pricing are made in stage one. Stage one decisions are made with energy price states in stage two of nature unknown subject to capacity and pricing decisions made in the first stage, optimal operating decisions are made in stage two for each energy price state of nature. Stage two decisions include levels of processing activities by mode and period and storage activities by intermediate product and time period, as shown in the algebraic model above. This multi-stage stochastic programming framework is designed to account for changes in electricity prices and other stochastic events influencing input prices, product prices, resource availabilities, input requirements or process yields. This framework is illustrated in Figure 2, which represents the theoretical firm's problem in a decision tree. With the DSP model, the stochastic nature of problem parameters, such as electricity prices, are characterized with several discrete "states of nature", represented by the stage two branches of the decision tree.

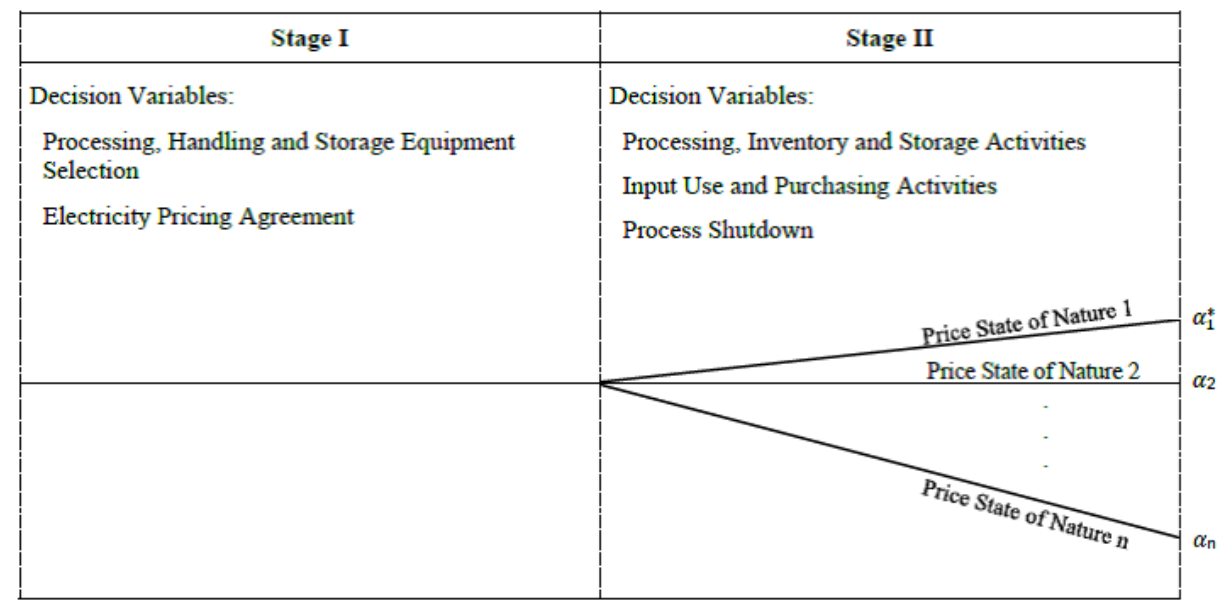

Figure 2. Decision tree illustrating the stochastic programming framework

Note. The $\alpha$ values represent the probabilities of the joint events associated with each terminal branch.

Further, the DSP framework allows for a sequence of production, resource use and product marketing decisions over time as random events occur. Decisions made at a particular point in time are made with probabilistic knowledge of future states of nature, and the consequences of current decisions for future decisions is captured through the constraints of the optimization model. For example, in cement processing, the curtailment of a process for purposes of reducing electricity use when rates are high would lead to an accumulation of intermediate product inventories for input to the curtailed subsequent process, and depletion of inventories of the output of the process. To analyze demand reduction policies for electricity, electricity price states of nature will be defined to represent the stochastic nature of these prices. This might be accomplished by using historical price series as states, or by constructing a simulation model as a state generator driven by weather and other important determinants of electricity prices. For this analysis, stage one decisions involve the level of finish grinding capacity. Once grinding capacity is selecting, processing storage decisions are optimized for each electricity price state.

The model was build using GAMS, the Generalized Algebraic Modeling System, (Chattopadhyay, 1999; Williams, 2013). GAMS is a high-level language for building, solving and analyzing mathematical programming models. A wide range of solution algorithms may be used for solving large scale optimization problems. The model used in this study is a mixed integer, linear programming model. The model was optimized using the GUROBI solver. (Note 7) The exact dimensions of the model vary slightly by scenario, but included 
approximately 75 thousand constraints and 128 thousand variables, approximately 4,500 of which were integer. (Note 8).

To simplify the problem, stage two decisions were optimized in GAMS for each of several discrete levels of grinding capacity. An overall optimal strategy for each capacity level was found, then, by solving the stage two problem for each electricity price state of nature.

\subsection{Analysis and Model Parameters}

To demonstrate the use of the stochastic programming model of production planning of a representative cement plant, an analysis was conducted focusing on scheduling of the finish grinding operation due to relatively flexible nature of electricity consumption during this stage of production. The model allows for adjusting the timing of finish grinding, a stage two decision (See Figure 2), in response to changing electricity prices under different price states of nature. Stage one decisions involve the level of finish grinding capacity, set at discrete levels from $100 \%$, the baseline capacity scenario which is balanced to match the kiln processing rate, to $105 \%$, $110 \%$ and $115 \%$ capacity scenarios, which allow for finish grinding to be delayed to avoid electricity use when price, and the market demand for electricity, is high without reducing cement output. The model is solved for thirty minute time periods over a three month planning horizon. (Note 9) To explore seasonal differences in price patterns, summer and winter planning horizons are analyzed (e.g., higher real-time prices in summer than winter in MISO market). Three years of observed electricity prices (i.e. 2016, 2017 and 2018) are used as states of nature, each assumed equally likely (Note 10).

\subsection{Raw Materials and Electricity Use}

The primary raw materials for producing cement are limestone and clay. To produce one ton of cement, approximately $1.372 \mathrm{~kg}$ of limestone, $187.5 \mathrm{~kg}$ of clay, and $37.7 \mathrm{~kg}$ of other materials are required. (Note 11 ) There may be some loss in the total amount of inputs used during some of the production activities and, therefore, the production coefficients in each step may vary depending on the equipment. Input requirements used in the model, collected from the Portland Cement Association, USGS Reports and other sources (Note 12), are summarized in Table A1 of the Appendix (Olsen et al., 2010; Madlool et al., 2011; Madlool et al., 2013) (Note 13).

Cement production requires various energy sources during the production process: coal, electricity, fuel and natural gas (Olsen et al., 2010). Coal is primarily used in the kiln process for melting raw mix, while electricity is used across all of the production activities. (Note 14) Approximately $140 \mathrm{kWh}$ of electricity is used to produce a ton of cement, excluding use for in-plant lighting and dust-collection (Madlool et al., 2011). The majority of the electricity is used in the kiln ( $86 \mathrm{kWh} / \mathrm{ton})$, whereas approximately $15 \mathrm{kWh} /$ ton of electricity is used during raw milling and $37 \mathrm{kWh} /$ ton of electricity is used during finish grinding. Plant lights and dust-collection consume approximately $10 \mathrm{kWh} /$ ton. More specifically, raw milling uses approximately $11 \%$, kiln uses approximately 50\% and finish grinding uses approximately $33 \%$ of the total electricity consumed to produce a ton of cement. The distribution of electricity consumption across production activities is shown in Figure 3.

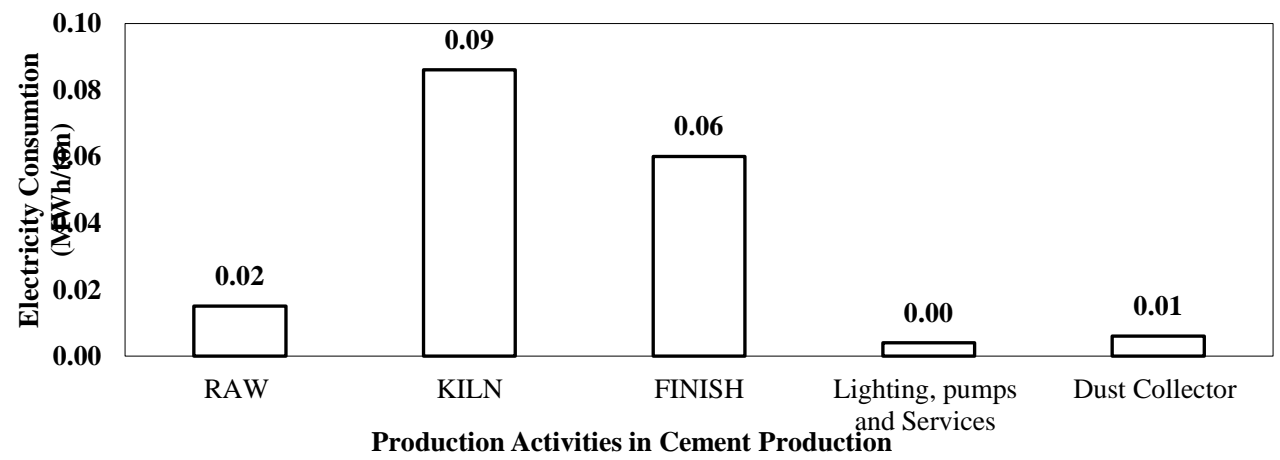

Figure 3. Electricity consumption during cement production

\subsection{Real-Time Electricity Prices}

Real-time electricity price data for the analysis is from the Midcontinent Independent System Operator (MISO) electricity market. Electricity prices vary throughout the day across regional pricing hubs (i.e., MN, IL, IN). Daily real-time prices are the highest during on-peak hours, which are often between 8am and 10pm in the MISO 
region. Similarly, off-peak hours are defined as the times when real-time electricity prices are the lowest. Off-peak hours are when the market demand for electricity is lower. Further, there is variation in real-time prices across seasons, and MISO region is known as summer peaking. Although average prices in winter were higher between 2016 and 2018, MISO market often has higher on-peak real-time prices in summer. Figure 4 illustrates the real-time market prices on summer and winter using the historical MISO market prices in 2016, 2017 and 2018.
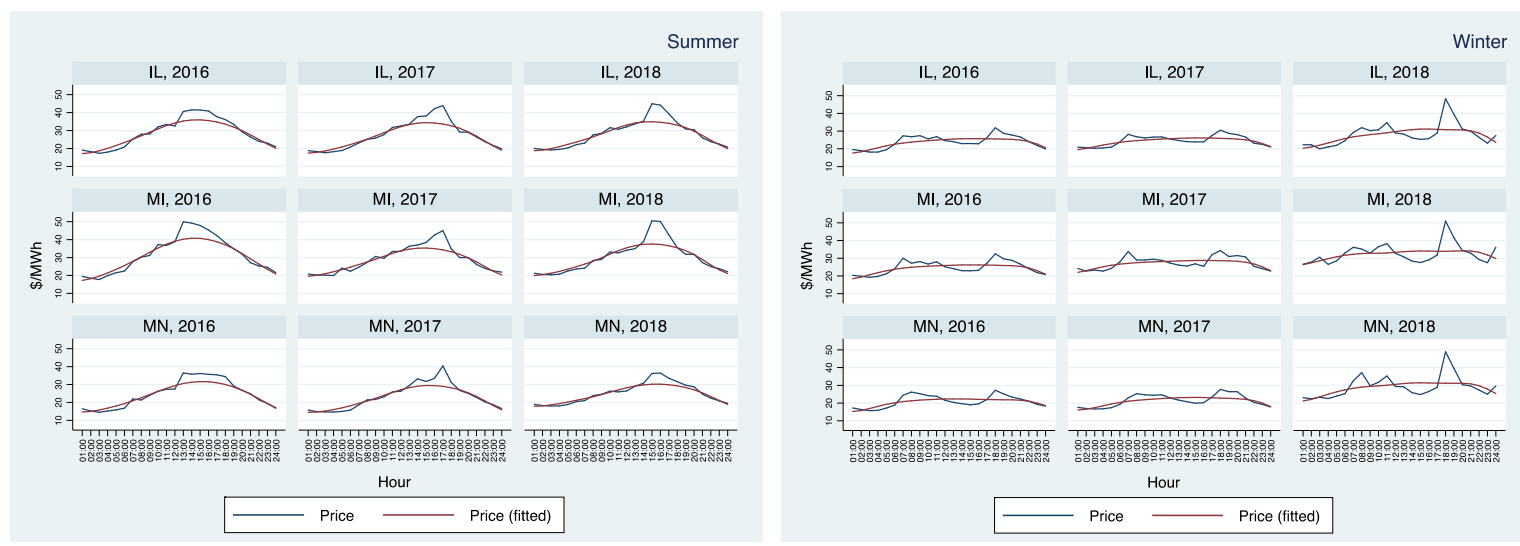

Figure 4. Real-time electricity prices of summer and winter seasons in MISO sub-regional electricity market hubs

Historical 5-minute real-time market prices are collected between 2016 and 2018, with each year used as states of nature that are assumed to be equally likely (i.e. each electricity price state of nature has a probability of 1/3). To conform to the 30 minute price periods used in the model, the price in the first five minutes of each period is used in each year (state of nature) and in three pricing hubs: Minnesota, Illinois and Michigan. Descriptive statistics for daily average real-time prices are shown in Table 1 for summer and winter, and for each of the three markets.

Table 1. Hourly average real-time prices in the MISO market: summer and winter

\begin{tabular}{ccccccc}
\hline & \multicolumn{3}{c}{ Summer (cents/kWh) } & \multicolumn{3}{c}{ Winter (cents/kWh) } \\
\hline Minnesota & $\mathbf{2 0 1 6}$ & $\mathbf{2 0 1 7}$ & $\mathbf{2 0 1 8}$ & $\mathbf{2 0 1 6}$ & $\mathbf{2 0 1 7}$ & $\mathbf{2 0 1 8}$ \\
Michigan & 2.5 & 2.3 & 2.5 & 1.9 & 2.3 & 2.6 \\
Illinois & 3.2 & 2.9 & 3.0 & 2.2 & 2.8 & 3.1 \\
\hline
\end{tabular}

\section{Results}

The solution of this cement production model determines the processing and resource use schedule that maximizes expected net revenue. In the baseline scenario (i.e. 100\% finish grinding capacity), the plant has capacities for each stage of production that are matched, so electricity use can only be reduced by producing less cement in the three month planning horizon. When excess finish grinding capacity is added (i.e. $105 \%$ and $110 \%$ finish grinding capacity), it becomes possible to delay finish grinding without reducing total cement production so long as sufficient capacity is available in later periods to complete production. More importantly, it also means that electricity consumption is curtailed during the interruption period and electricity consumption is deferred to be used when the real-time price of electricity is at off-peak. The intermediate product of the kiln and cooling processes, clinker, is held in inventory when finish grinding is delayed. Results of particular interest include the electricity cost in a production cycle, and the amount of time the cement plant shuts down, or otherwise delays the finish grinding activity. These outcomes depend on the facility location, season, and electricity price state of nature, as well as the finish grinding capacity.

Under baseline scenario, the expected net revenue in summer is approximately $1 \%$ higher than the expected revenue in winter for all regions. This is consistent with higher real-time prices in summer than in winter. The highest expected net revenue from production occurs in the summer for all regions. Figure 5, presents the comparison of expected net revenues for summer and winter for the baseline capacity scenario. 


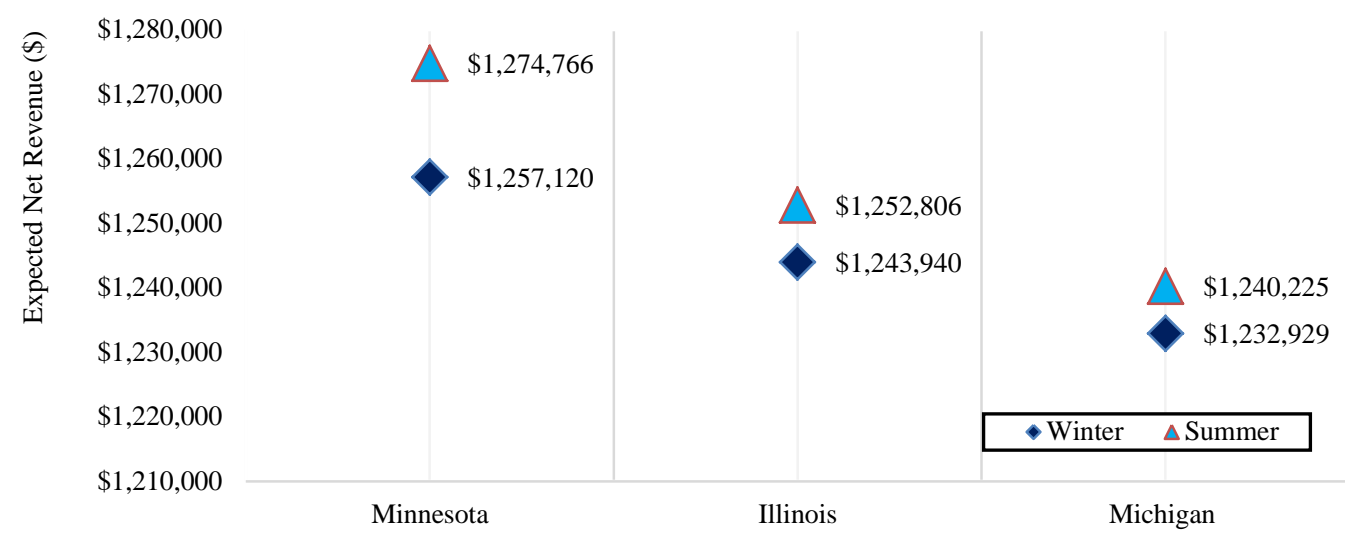

Figure 5. Expected net revenue for baseline capacity - Minnesota, Illinois and Michigan

Further, with higher excess finish grinding capacity, expected net revenue increases because finish grinding may be rescheduled to avoid the highest electricity prices. However, note that as more capacity is added, net revenue increases at a decreasing rate because the most extreme price events have already been avoided. The benefit of added capacity must be weighed against the associated capital recovery costs and maintenance costs. We focused here on the operating income benefit since the equipment changes and associated capital recovery costs would require additional engineering analyses that were beyond the scope of this study. To be profitable, the additional expected operating income must exceed the capital recovery cost of the additional finish grinding capacity. Figure 6 illustrates the expected net revenue, as well as net revenue under each electricity price state, at different finish grinding capacities with winter prices in Minnesota.

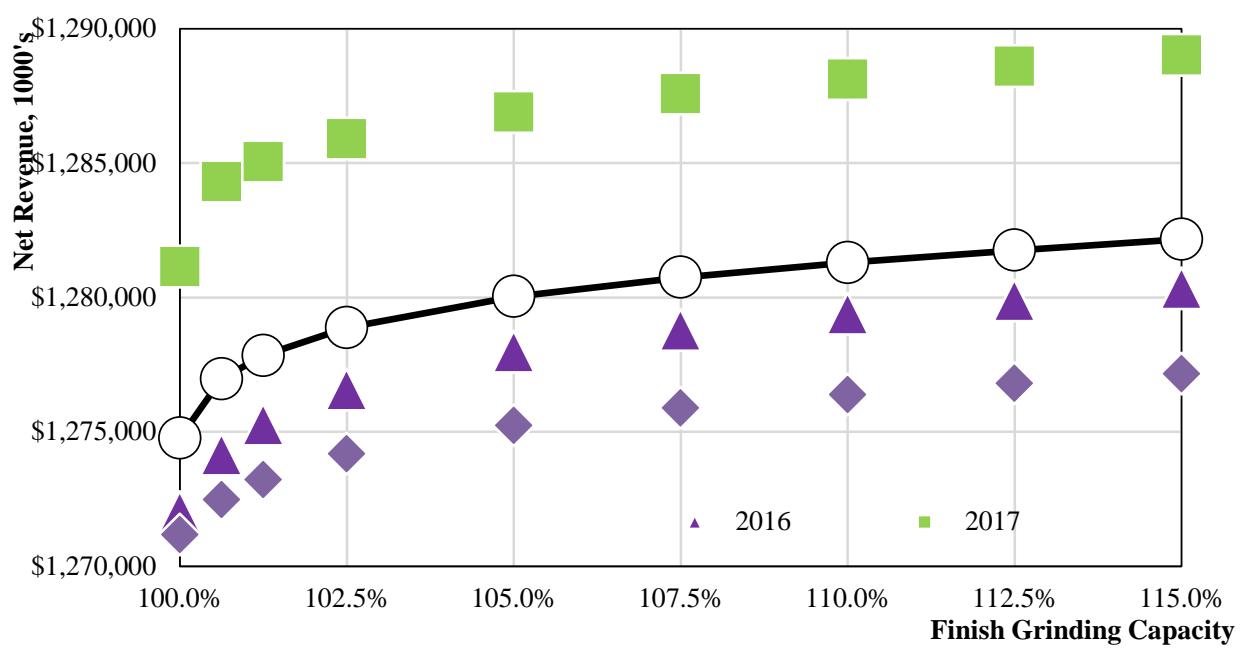

Figure 6. Expected net revenue for different capacity in Minnesota - Summer

Note that with higher excess capacity for finish grinding, the total number of hours of delay in finish grinding use also increases, allowing electricity use to be reduced when electricity prices, and generating costs, are high. There may be up to 397 operating periods (i.e., equivalent of 199 hours in a summer period) of delay in summer in the $10 \%$ excess finish grinding capacity scenario. In $15 \%$ excess capacity scenario, up to 570 operating periods (equivalent of 285 hours in a summer period) are delayed. The total duration of interruption during finish grinding is always higher in summer, when the average real-time peak prices are often higher than in winter.

Further, the finish grinding activity is often interrupted (i.e., production operation is delayed) at the times when the real-time prices are at peak. In figure 7, we plot the time periods, when the Minnesota plant delays finish grinding in summer excess capacity in finish grinding activity. Each item in Figure 7 represents a thirty minute processing period: the combination of time of day and electricity price that the finish grinding activity is interrupted. Analysis results show that majority of the interruption occur during on-peak hours, between $8 \mathrm{am}$ and 
$10 \mathrm{pm}$ for each excess capacity scenario. The average real-time electricity prices in Minnesota ranges between [\$23.2/MWh-\$25.2/MWh] in summer (See Table 1), while we find delays in operation are at the highest electricity prices (e.g., higher than $\$ 2000 / \mathrm{MWh}$ ).
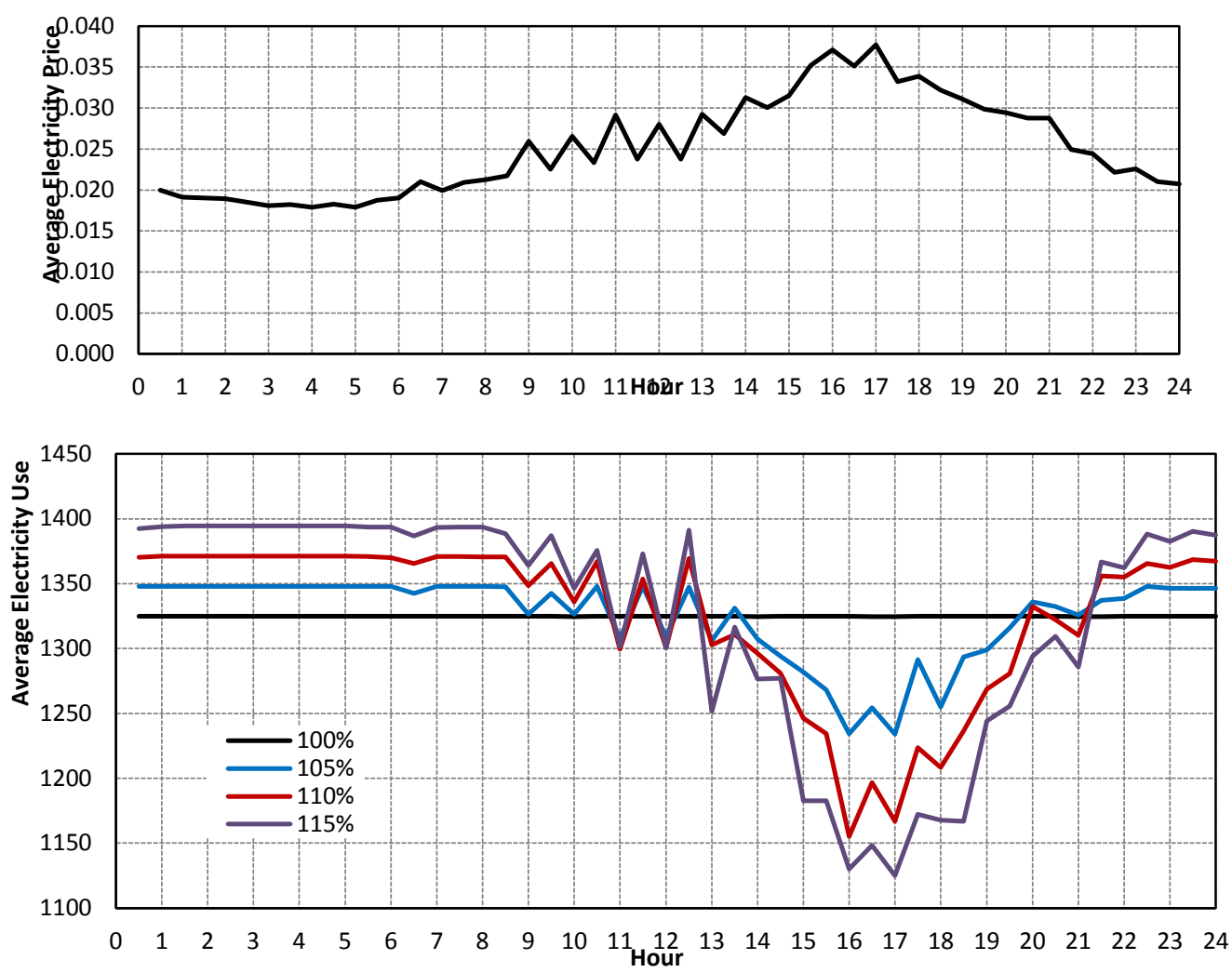

Figure 7. Average real time electricity prices by time of day for Minnesota, Summer 2018, and Average Note. Optimal Electricity Use by the Cement Plant with 100\%, 105\%, 110\% and 115\% Finish Grinding Capacity.

Results show that if a cement plant is given the option to track real-time prices in the market rather than paying a fixed retail rate, it is economical for this plant to reschedule electricity consumption when the electricity prices are at their peak during finish grinding. The plant also makes roughly $20 \%$ additional net revenue, less the capital recovery cost of added finish grinding capacity, under the real-time pricing contract, while the total amount of cement production remains constant. This shows that the electricity consumption is scheduled the times when the cost of electricity is lower and the plant does not have to give up on planned production levels under $15 \%$ excess finish grinding capacity scenario.

Tables 2 and 3, below, summarize the expected net revenue value (\$), total cement production (metric tons), total number of thirty minute delays, total electricity consumed $(\mathrm{kWh})$ during production cycle and the average price paid for electricity $(\$ / \mathrm{KWh})$ for each states of nature for each capacity scenario. Specifically, results for Minnesota winter and Minnesota summer are presented in Table 2 and Table 3, respectively. Results for Illinois winter and Illinois summer are presented in Appendix Table 2 and in Table 3, respectively. Results for Michigan winter and Michigan summer are presented in Appendix Table 4 and in Table 5, respectively.

Finally, it is important to note that in the baseline scenario results should be interpreted carefully. Any operational delay other than finish grinding would be achieved by producing less cement and this is only optimal when it happens at the end of each season, so the processes before the finish grinding, as well as other operations, can be shut down early. For example, this happens when the plant does not need to restart kiln at the very end of the production period and when the electricity prices are high during the last time period. The baseline scenario results are presented in order to provide a comparison to the excess capacity scenarios, which provide the primary outcomes of this analysis. 
Table 2. Summary of optimal solutions by finish grinding capacity for minnesota winter electricity price states of nature

\begin{tabular}{|c|c|c|c|c|c|}
\hline $\begin{array}{c}\text { Finish Grinding } \\
\text { Capacity }\end{array}$ & $\begin{array}{c}\text { Electricity } \\
\text { Price State of Nature }\end{array}$ & Net Revenue & $\begin{array}{c}\text { Cement Production } \\
\text { MT }\end{array}$ & $\begin{array}{c}\text { Finish Grinding } \\
\text { Delay, Hours }\end{array}$ & $\begin{array}{c}\text { Average Electricity } \\
\text { Price Paid, cents/KWH }\end{array}$ \\
\hline \multirow[t]{5}{*}{$100 \%$} & $2015-2016$ & $\$ 1,278,615$ & 36,414 & 0.1 & 1.90 \\
\hline & 2016-2017 & $\$ 1,256,181$ & 36,414 & 0.1 & 2.29 \\
\hline & $2017-2018$ & $\$ 1,236,565$ & 36,337 & 9.1 & 2.59 \\
\hline & & & 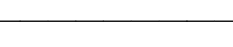 & xpected Values* & \\
\hline & & $\$ 1,257,120$ & 36,388 & 3.1 & 2.26 \\
\hline \multirow[t]{5}{*}{$105 \%$} & $2015-2016$ & $\$ 1,280,549$ & 36,414 & 203.5 & 1.87 \\
\hline & 2016-2017 & $\$ 1,259,616$ & 36,414 & 203.5 & 2.23 \\
\hline & 2017-2018 & $\$ 1,242,991$ & 36,414 & 203.5 & 2.52 \\
\hline & & & 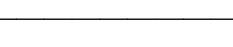 & xpected Values ${ }^{*}$ & \\
\hline & & $\$ 1,261,052$ & 36,414 & 203.5 & 2.21 \\
\hline \multirow[t]{5}{*}{$110 \%$} & $2015-2016$ & $\$ 1,281,113$ & 36,414 & 388.4 & 1.86 \\
\hline & 2016-2017 & $\$ 1,260,560$ & 36,414 & 388.4 & 2.22 \\
\hline & $2017-2018$ & $\$ 1,244,090$ & 36,414 & 388.4 & 2.50 \\
\hline & & & $-\mathrm{E}$ & cted Values ${ }^{*}$ & \\
\hline & & $\$ 1,261,921$ & 36,414 & 388.4 & 2.19 \\
\hline \multirow[t]{5}{*}{$115 \%$} & $2015-2016$ & $\$ 1,281,527$ & 36,414 & 557.3 & 1.85 \\
\hline & 2016-2017 & $\$ 1,261,201$ & 36,414 & 557.3 & 2.20 \\
\hline & $2017-2018$ & $\$ 1,244,775$ & 36,414 & 557.3 & 2.49 \\
\hline & & & $-\mathrm{Ex}_{1}$ & Values* & \\
\hline & & $\$ 1,262,501$ & 36,414 & 557.3 & 2.18 \\
\hline
\end{tabular}

Note. Price states of nature are assumed to be equally likely, so the probability of each state is $1 / 3$.

Table 3. ummary of optimal solutions by finish grinding capacity for minnesota summer electricity price states of nature

\begin{tabular}{|c|c|c|c|c|c|}
\hline $\begin{array}{c}\text { Finish Grinding } \\
\text { Capacity }\end{array}$ & $\begin{array}{c}\text { Electricity } \\
\text { Price State of Nature }\end{array}$ & Net Revenue & $\begin{array}{c}\text { Cement Production } \\
\text { MT }\end{array}$ & $\begin{array}{c}\text { Finish Grinding } \\
\text { Delay, Hours }\end{array}$ & $\begin{array}{c}\text { Average Electricity } \\
\text { Price Paid, cents/KWH }\end{array}$ \\
\hline \multirow[t]{5}{*}{$100 \%$} & $2015-2016$ & $\$ 1,272,000$ & 37,232 & 0.1 & 2.51 \\
\hline & $2016-2017$ & $\$ 1,281,129$ & 37,156 & 9.1 & 2.31 \\
\hline & $2017-2018$ & $\$ 1,271,168$ & 37,232 & 0.1 & 2.52 \\
\hline & & \multicolumn{4}{|c|}{ _ Expected Values ${ }^{*}$} \\
\hline & & $\$ 1,274,766$ & 37,207 & 3.1 & 2.45 \\
\hline \multirow[t]{5}{*}{$105 \%$} & $2015-2016$ & $\$ 1,277,972$ & 37,232 & 208.1 & 2.41 \\
\hline & 2016-2017 & $\$ 1,286,883$ & 37,232 & 208.1 & 2.25 \\
\hline & $2017-2018$ & $\$ 1,275,226$ & 37,232 & 208.1 & 2.45 \\
\hline & & \multicolumn{4}{|c|}{ — Expected Values ${ }^{*}$} \\
\hline & & $\$ 1,280,027$ & 37,232 & 208.1 & 2.37 \\
\hline \multirow[t]{5}{*}{$110 \%$} & $2015-2016$ & $\$ 1,279,379$ & 37,232 & 397.1 & 2.38 \\
\hline & 2016-2017 & $\$ 1,288,121$ & 37,232 & 397.1 & 2.23 \\
\hline & $2017-2018$ & $\$ 1,276,378$ & 37,232 & 397.1 & 2.43 \\
\hline & & \multicolumn{4}{|c|}{ Expected Values ${ }^{*}$} \\
\hline & & $\$ 1,281,293$ & 37,232 & 397.1 & 2.35 \\
\hline \multirow[t]{5}{*}{$115 \%$} & $2015-2016$ & $\$ 1,280,324$ & 37,232 & 569.8 & 2.37 \\
\hline & $2016-2017$ & $\$ 1,289,010$ & 37,232 & 569.8 & 2.22 \\
\hline & $2017-2018$ & $\$ 1,277,146$ & 37,232 & 569.8 & 2.42 \\
\hline & & \multicolumn{4}{|c|}{ - Expected Values ${ }^{*}$} \\
\hline & & $\$ 1,282,160$ & 37,232 & 569.8 & 2.34 \\
\hline
\end{tabular}

Note. Price states of nature are assumed to be equally likely, so the probability of each state is $1 / 3$.

\subsection{Comparing Emissions and Electricity Use}

Using the optimal electricity consumption levels for every thirty minute production period, we show the relationship between the plant's hourly electricity usage $(\mathrm{kWh})$, the real-time prices and hourly $\mathrm{CO}_{2}$ emissions, 
which are obtained from the Environmental Protection Agency's Continuous Emissions Monitoring System data by state for Summer 2018 in Minnesota. Table 4 presents the total electricity cost under baseline capacity and electricity cost given the optimal processing schedules with excess processing capacities of $105 \%, 110 \%$ and $115 \%$. The total level of hourly $\mathrm{CO}_{2}$ emissions (tonnes) associated with the optimal schedule of electricity use is also shown. The plant starts to alter electricity use during the highest electricity price hours, while the plant does not change the total amount of electricity use with baseline capacity since there is no flexibility in production to interrupt without altering production levels.

Table 4. lectricity cost and emissions results, given summer 2018 real time prices in Minnesota

\begin{tabular}{cccc}
\hline \multicolumn{4}{c}{ Finish Grinding Capacity } \\
\hline $100 \%$ & $105 \%$ & $110 \%$ & $115 \%$ \\
\hline \multicolumn{5}{c}{ Total Electricity Cost and \% Change from Base Capacity ${ }^{*}$} \\
\hline 147,502 & 143,430 & 142,277 & 141,509 \\
--- & $-2.8 \%$ & $-3.5 \%$ & $-4.1 \%$ \\
\hline \multicolumn{5}{c}{ Emissions from Electricity Generation and \% Change from Base Capacity ${ }^{* *}$} \\
\hline--- & 27,943 & 27,995 & 28,020 \\
& $(0.24 \%)$ & $(0.43 \%)$ & $(0.52 \%)$ \\
\hline
\end{tabular}

Note. ${ }^{*}$ The values shown for each location represent the total electricity cost by level of finish grinding capacity. Below each result in parentheses is the percentage change in electricity cost from the base capacity of $100 \%$

${ }^{* *}$ Shown here are the $\mathrm{CO}_{2}$ emissions associated with electricity generation for each location and each level of finish grinding capacity. Below each result in parentheses is the percentage change in emissions from the base capacity of $100 \%$.

As Table 4 shows, $\mathrm{CO}_{2}$ emissions increase as excess capacity in finish grinding increases. When the plant managers are able to shift electricity consumption as a result of increased processing capacity increases and the plant shifts electricity use to off-peak hours (i.e., during the night). With baseload electricity generation primarily from coal units, emissions levels are highest in the off-peak hours. Figure 8 illustrates the hourly $\mathrm{CO}_{2}$ emissions profile at baseline and each excess capacity scenario, which suggests that the $\mathrm{CO}_{2}$ emissions would go down slightly while electricity costs are more significantly reduced.

However, the magnitude of the effect may be smaller and the direction of the net effect should certainly be studied more carefully (i.e., these results are sensitive to the regional market generation mix) in the future research.

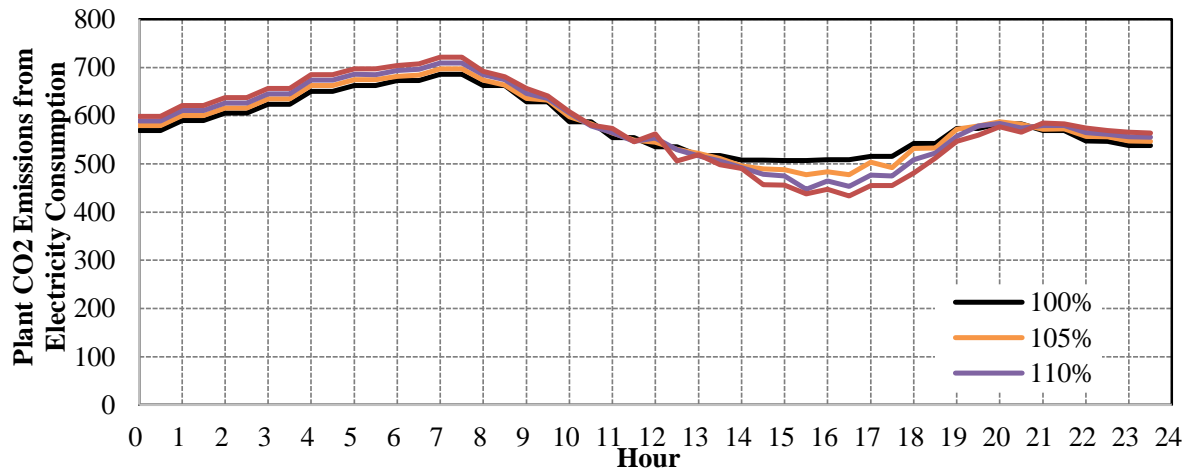

Figure 8. Total hourly emissions in summer 2018 in Minnesota for baseline capacity (100\%) and excess capacity scenarios $(105 \%, 110 \%$ and $115 \%)$

\section{Discussion}

Dynamic pricing provides electricity users the flexibility to choose to purchase electricity at the times when the cost of electricity is cheaper, which can provide several economic and potentially environmental benefits. Many previous studies have demonstrated that customers are able to respond to the electricity price changes, if they are given the option to track real-time electricity prices (Veall, 1986; Fan \& Hyndman, 2011; Lijesen, 2007; Schwarz \& Taylor, 2002; Patrick \&Wolak, 2011; Genc, 2016). This study contributes to the literature by proposing a discrete stochastic mathematical optimization method by specifically modelling real-time cement production 
planning.

Additionally, this study provides a case study that demonstrates economic and potential environmental benefits of adopting real-time pricing for the cement operations by allowing the plant to adjust electricity consumption with varying electricity rates rather than fixed time-of-use rates. In this paper, what specifically is shown as allowing the cement plant to reschedule operation in the finish grinding would be a way to reduce electricity use when prices are high, shifting that use to a time period when electricity is cheaper. Based on the results of this study, there are several benefits of real-time pricing to the large energy users like cement plants. First, real-time pricing lowers the total electricity costs during production. The economic savings are more obvious during summer, when the prices are considerably higher than average prices in most places. Although we were not able to show the overall electricity savings due to data limitations, this modelling framework has the potential to address this question as well. Second, the cement plant in this case study, demonstrates that tracking real-time pricing provides the cement plant an incentive for adjusting electricity use and scheduling electricity consumption in association with increasing electricity prices during finish grinding activity. This possibly decreases the average electricity price paid during finish grinding. Finally, another important finding of this analysis is that reducing electricity use with real-time pricing does not necessarily alter overall profitability of the production. The cost savings from altering the processing schedule must be weighed against the cost of increased finish grinding and clinker storage capacities.

In addition to the benefits of the energy management in an energy intensive industry, this study also informs electric utilities and market operators on designing their customer pricing programs. For example, this study demonstrates the importance of considering operational flexibilities, the ability to curtail during finish grinding activity in this case study, in electricity consumption in certain production processes. Particularly, rescheduling large electricity consumption can benefit utilities' operational planning for peak generation and market operators' decision on generation units, if some of these large users can serve as a capacity resource in the electricity markets. Finally, if real-time pricing can be adopted by such large industrial customers and these customers are able to reschedule electricity consumption towards off-peak periods, avoided generation has also a strong potential environmental implications, while this clearly requires further empirical or analytical research.

\subsection{Study Limitations and Topics for Future Research}

The best approach to managing model size and data requirements in multi-stage stochastic programming models is problem specific. In the context of the cement processing model used in this study, the processing decisions in a particular operating period are influenced by past processing decisions and existing inventories of intermediate products (clinker), and the implicit, stochastic value of current, processing capacity. Allowing the inventory of clinker to increase by processing less than the current period clinker production increases the demand for future finish grinding capacity and limits opportunities to reduce future electricity use by shutting down. The goal in designing the multi-stage model is to accurately capture the implicit value of future processing capacity. The implementation of real time electricity price policies would create risk management challenges to electricity customers and a need for new risk management strategies. Stochastic programming models of the type presented here could be used to test decision rules that consider the opportunity cost of capturing current electricity cost savings when doing so reduces future opportunities to do so. For example, the model used in this study could explore the extent to which adoption of a particular rule for shutting down finish grinding would capture electricity cost savings occurring in the perfect foresight case. These decision rules would need to consider current resource and market conditions, such as clinker inventories and electricity prices, a determinants of future electricity price movements, such as weather forecasts.

We use MISO price data as a first approximation of the electricity price dynamics that could occur under real time pricing. The dynamics of electricity markets would certainly change under pricing policies that are designed to make industrial electricity demand more responsive to market conditions. More research focusing on market behavior under alternative pricing policies is warranted. As a regulated market, opportunities exist to develop pricing schemes tailored to both the supply and demand sides of the electricity market, including aspects risk sharing that occur through markets. For instance, some combination of real-time pricing and time of use pricing could be designed to incent conservation in times of high demand, while dampening the price risk that would occur if companies paid the prices used to balance electricity generation across the grid.

A strength of multi-stage, discrete stochastic programming (DSP) models is the potential to capture the relationship between the sequence of decisions and the flow of information about the uncertain events that influence those decisions. The two-stage model used in this study supposed a first stage in which the size of processing machinery (finish grinding capacity) is selected, following by a second stage in which operating 
decisions are made for each of the 30-minute, intra-stage time periods over the three-month planning horizon decisions made under each electricity price state of nature. Critical attributes of DSP models involve when the decision maker know the outcome of random events in each stage relative to the timing of the decisions - what has been referred to as the information structure of the problem (Rae, 1971). In this study, we assume an information structure of complete knowledge of the past and present, so the plant manager knows the electricity price in all operating periods in stage two when operating decisions are made. Doing so allows us to explore the extent to which the scheduling of processing activities can be used to absorb real-time electricity price fluctuations. However, it assumes that operating decisions are made with perfect foresight of electricity prices in future periods, and therefor ignores the input price risk which would be inherent in processing decisions under real-time pricing. In our cement processing model, the risk associated with real-time electricity prices involves whether or not to shut down processing now given the known price state or save excess capacity to be used to shut down and conservation of electricity later. In order to model real time price risk, a multi-stage recourse model is suggested in which processing levels for the current period are selected with stochastic price states of nature in future periods. The producer's recourse, then, occurs in the form of future processing decisions. Operating periods in the cement plant model could become decision stages, with well-known implications for model size. The task adequately characterizing in each stage the prospective electricity price states of nature would arguably be the greatest challenge.

\section{Conclusions}

This paper provides an analytical framework for the adoption of real-time pricing using a discrete stochastic production model. A cement production planning model is developed considering the real-time variation in electricity prices. Results show that the electricity price peaks are higher during summer in the MISO market, and the analysis shows that the cement plant responds more to peaking prices during the summer compared to winter season. Although there are regional price variations across the MISO footprint, this analysis shows that the cement plant consumes electricity when it is cheaper with the real-time pricing. Moreover, the plant reduces electricity consumption during peak hours and schedules electricity use when the price of electricity is cheaper, while maintaining the expected net revenue from the total production when there is excess finish grinding capacity.

This paper studies the economic implications of dynamic pricing in a cement manufacturing plant using mathematical optimization methods. Although there are data limitations on cement production parameters, this study provides a novel case on the economic and operational implications of dynamic pricing in a representative cement plant. This study aims to build improved understanding of a particular industry's electricity use and explore adoption of dynamic pricing on production and profitability.

Fuel-switching (alternatively, on-site generation) within the kiln activity, allowing for more efficient use of electricity during kiln process in addition to relaxing the modelling assumptions on delaying operation finish grinding could be studied in the future.

\section{Disclaimer}

The opinions expressed are author's and do not reflect the views of Charles River Associates or any of its respective affiliates.

\section{References}

Alcott, H. (2011). Rethinking real-time electricity pricing. Resource and Energy Economics, 33(4), 820-842. https://doi.org/10.1016/j.reseneeco.2011.06.003

Apland, J., \& Grant, H. (1993). Discrete Stochastic Programming: Concepts, Examples and a Review of Empirical Applications (Staff Paper, pp. 93-21). Department of Agricultural and Applied Economics, University of Minnesota.

Batista de Silva, H., \& Santiago, L. P. P. (2015). On the trade-off between real-time pricing and the social acceptability costs of demand response. Renewable and Sustainable Energy Reviews. https://doi.org/10.1016/j.rser.2017.05.219

Bharvirkar, R., \& Goldman, C. (2008). Coordination of Retail Demand Response with Midwest ISO Wholesale Markets. Analysis, (May). https://doi.org/10.2172/948132

Borenstein, S. (2005). The Long-Run Efficiency of Real-Time Electricity Pricing. The Energy Journal, 26(3), 93-116. https://doi.org/10.5547/ISSN0195-6574-EJ-Vol26-No3-5

Chao, H. (2009). An Economic Framework of Demand Response in Restructured Electricity Markets. Response, 
$1-48$.

Retrieved

from

http://www.hks.harvard.edu/hepg/Papers/2009/DemandResponseinRestructuredMarkets02-08-09.pdf

Chattopadhyay, D. (1999). Application of General Algebraic Modelling System to Power System Optimization. IEEE Transactions on Power Systems, 14(1), 15-22. https://doi.org/10.1109/59.744462

Cooke, D. (2011). Empowering customer choice in electricity markets. Information Paper. Retrieved from http://www.iea.org/publications/freepublications/publication/Empower.pdf

Eid, C., Koliou, E., Valles, M., Reneses, J., \& Hakvoort, R. (2016). Time based pricing and electricity demand-response: Existing barriers and next steps. Utilities Policy, 40(2016), 15-25. https://doi.org/10.1016/j.jup.2016.04.001

Eryilmaz, D., Smith, T. M., \& Homans, F. (2016). Price Responsiveness in Electricity Markets: Implications for Demand Response in the Midwest. The Energy Journal, 38(1). https://doi.org/10.5547/01956574.38.1.dery

Fan, S., \& Hyndman, R. J. (2011). The Price Elasticity of Electricity Demand in South Australia. Journal of Energy Policy, 39(6), 3709-3719. https://doi.org/10.1016/j.enpol.2011.03.080

Faruqui, A., Hajos, A., Hledik, R. M., \& Newell, S. A. (2010). Fostering economic demand response in the Midwest ISO. Energy, 35(4), 1544-1552. https://doi.org/10.1016/j.energy.2009.09.014

Genc, T. (2016). Measuring Demand Responses to Wholesale Electricity Prices Using Market Power Indices. Energy Economics, 56(2016), 247-260. https://doi.org/10.1016/j.eneco.2016.03.013

Gielen, D., \& Taylor, M. (2007). Modelling Industrial Energy Use: The IEA's Energy Technology Perspectives. Energy Economics, 29(2007), 889-912. https://doi.org/10.1016/j.eneco.2007.01.008

Hailong, L, Sun, Q., Zhang, Q., \& Wallin, F. (2014). A review of the pricing mechanisms for district heating systems. Renewable and Sustainable Energy Reviews, 42, 56-65. https://doi.org/10.1016/j.rser.2014.10.003

Hamdani, R. (2000). Ball Mill Driven with Gearless Mill Drive. Cement Industry Technical Conference, 2000 IEEE-IAS/PCA, 55-68, 7-12. https://doi.org/10.1109/CITCON.2000.848510

Hanle, L. J. (2004). $\mathrm{CO}_{2}$ Emissions Profile of the U.S. Cement Industry. US Environmental Protection Agency, 13. Retrieved from http://infohouse.p2ric.org/ref/43/42552.pdf

Hillier, F. S. (2012). Introduction to Operations Research. Tata McGraw-Hill Education.

International Energy Agency (IEA). (2010). Energy Technology Perspectives: Scenario and Strategies to 2050. Retrieved from https://www.iea.org/publications/freepublications/publication/etp2010.pdf

KEMA Inc., \& Lawrence Berkeley National Laboratory. (2005). Industrial Case Study: The Cement Industry (pp. 14-17).

Khan, A. R., Mahmood, A., Safdar, A., Khan, Z. A., \& Khan, N. A. (2016). Load forecasting, dynamic pricing and DSM in smart grid: A review. Renewable and Sustainable Energy Reviews, 54, 1311-1322. https://doi.org/10.1016/j.rser.2015.10.117

Kramer, J. K., Masanet, E., Xu, T., \& Worrel, E. (2009). Energy Efficiency Improvement and Cost Saving Opportunities in the Pulp and Paper Industry: An Energy Star Guide for Energy Managers. Retrieved from http://www.energystar.gov/ia/business/industry/downloads/Pulp_and_Paper_Energy_Guide.pdf

Lijesen, M. G. (2007). The real-time price elasticity of electricity. Energy Econ, 29(2), 249-58. https://doi.org/10.1016/j.eneco.2006.08.008

Madlool, N. A., Saidur, R., Hossain, M. S., \& Rahim, N. A. (2011). A critical review on energy use and savings in the cement industries. Renewable and Sustainable Energy Reviews, 15(4), 2042-2060. https://doi.org/10.1016/j.rser.2011.01.005

Madlool, N. A., Saidur, R., Rahim, N. A., \& Kamalisarvestani, M. (2013). An overview of energy savings measures for cement industries. Renewable and Sustainable Energy Reviews, 19, 18-29. https://doi.org/10.1016/j.rser.2012.10.046

Mathews, E., Kleingeld, M., Van Der Bijl, J., \& Jordaan, N. (2007). Real-time Energy Management in the Cement Industry. Presented at the Industrial and Commercial Use of Energy Conference, Cape Peninsula Institute of Technology.

McCarl, B. A., \& Spreen, T. (1997). Applied Mathematical Programming Using Algebraic Systems. Cambridge, MA. 
Mendez-Pinero, M. I., \& Colon-Vazques, M. (2013). Economic Analysis of Alternatives for Optimizing Energy Use in Manufacturing Companies. Energy Economics, 40(2013), 46-154. https://doi.org/10.1016/j.eneco.2013.06.001

MISO. (2013). Annual Market Assessment Report Information Delivery and Market Analysis June 2014. Retrieved https://www.misoenergy.org/Library/Repository/Report/Annual\%20Market\%20Report/2013\%20Annual\%2 0Market\%20Assessment\%20Report.pdf

Olsen, D., Goli, S., \& Faulkner, D. (2010). Opportunities for Energy Efficiency and Demand Response in the California Cement Industry. Lawrence Berkeley National Laboratory. Technical Report. https://doi.org/10.2172/1050705

Patrick, R. H., \& Wolak, F. A. (2011). Estimating the Customer-Level Demand for Electricity Under Real-Time Prices. NBER Working Paper Series, Cambridge MA.

Rae, N. A. (1971). Stochastic Programming, Utility, and Sequential Decision Problems in Farm Management. American Journal of Agricultural Economics, 53(3), 448-460. https://doi.org/10.2307/1238222

Rosenthal, R. E. (2017). GAMS: A User's Guide. GAMS Development Corporation, Washington DC.

Schwarz, P. M., \& Taylor, T. N. (2002). Industrial Response to Electricity Real-Time Prices: Short Run and Long Run. Journal of Economic Inquiry, 40(4), 597-610. https://doi.org/10.1093/ei/40.4.597

U.S. Department of Energy. (2015). Annual Energy Outlook.

U.S. DOE. (2006). Benefits of Demand Response in Electricity Markets and Recommendations for Achieving Them. Washington DC. Retrieved from https://eetd.lbl.gov/sites/all/files/publications/report-lbnl-1252d.pdf

U.S. Energy Information Administration. (2013). U.S. electricity sales have decreased in four of the past five years. December. Primary contributors: Robert McManmon, M. Tyson Brown. Retrieved from http://www.eia.gov/todayinenergy9/detail.cfm?id=14291

U.S. Energy Information Administration. (2014). Exploring the implications of low growth in electricity demand. June, New York. Retrieved from http://www.eia.gov/pressroom/presentations/sieminski_06242014.pdf

U.S. Life Cycle Inventory Database (USLCI). (2012). Portland Cement. National Renewable Energy Laboratory. Retrieved from https://uslci.lcacommons.gov/uslci/search

USGS. (2014). USGS Minerals information. International Minerals Statistics and Information. Retrieved from http://minerals.usgs.gov/

Van Oss, H. G. (2014). USGS, Cement Statistics. U.S. Geological Survey, Mineral Commodity Summaries, (703), 38-39. Retrieved from http://minerals.usgs.gov/minerals/pubs/commodity/cement/mcs-2014-cemen.pdf

Veall, M. R. (1986). Time-of-Use Rates and Peak Period Electricity Consumption: An Empirical Note. Energy Economics, 8(4), 257-262. https://doi.org/10.1016/0140-9883(86)90006-X

Wang, Y., \& Li, L. (2015). Time-of-use electricity pricing for industrial customers: A survey of U.S. utilities. Applied Energy, 149, 89-103. https://doi.org/10.1016/j.apenergy.2015.03.118

Williams, H. P. (2013). Model Building in Mathematical Programming (3rd ed). West Sussex, England: John Wiley and Sons Ltd.

Zarnikau, J. (1997). Taking Advantage of Real-Time Pricing Programs to Reduce Energy Costs in Manufacturing. White Paper in ACEEE Proceedings. Retrieved from http://aceee.org/files/proceedings/1997/data/papers/SS97_Panel1_Paper41.pdf

\section{Notes}

Note 1. These numbers may differ across countries. This study is based on US and Canada cement plant operations.

Note 2. It should be noted that the benefits reduced electricity use in peak demand times associated with real time pricing would result from the responses of many industrial users to the price signals. This response could be analyzed by modeling the electricity market as a whole, for instance using a sector modeling approach.

Note 3. MISO - Market Overview.

https://www.wapa.gov/About/the-source/Documents/2016/discussion-markets-todd-ramey-MISO.pdf 
Note 4. MISO Level 100- Energy and Operating Reserves Markets, April 23 , 2014. https://cdn.misoenergy.org/Level\%20100\%20-\%20Energy\%20and\%20Operating\%20Reserves 119103.pdf

Note 5. This model is constructed to allow the plant to delay electricity use during the finish grinding stage of production due to the dimensionality of the programming. This assumption can be relaxed to allow for delaying decisions using stochastic price states in other production processes. In addition, by including alternative process methods, the model can allow for alternative input combinations for a particular process - for example, alternative energy sources or combinations of raw materials. The alternative methods can also be used to capture the various fees and prices associated with a demand reduction policy. Transportation and labour costs are also assumed to be constant and negligible (i.e., it is assumed that the cement plant is located near the raw materials needed for the production process).

Note 6. For a general discussion of stochastic programming applications, see Apland and Hauer, and McCarl and Spreen.

Note 7. GUROBI is a solver package in GAMS for linear and quadratic programming including quadratically constrained programming, mixed-integer linear and quadratic programming and mixed-integer quadratically constrained programming. More information is available at: https://www.gams.com/latest/docs/S_GUROBI.html

Note 8. Note that GAMS allows flexible analytical modelling and the number of constraints and the use of solvers is specific to this case study. In other words, the model is flexible for modifications in fact, the number of constraints and the choice of the solver may change depending on the relaxed assumption of the current design of the model.

Note 9. We used 5-minute real-time market settlement data from MISO. In order to keep the model in a manageable size, we selected the first $5^{\text {th }}$ minute clearing prices for each 30 minutes.

Note 10. Winter season for each year is defined as follows: winter 2016 is defined as December 1, 2015 through February 28, 2016, winter 2017 is defined as December 1, 2016 through February 28, 2017, and winter 2018 is defined as December 1, 2017 through Feb 28, 2018.

Note 11. We obtained these material and energy input assumptions for Portland cement of which the inventory is from USLCI provided by National Renewable Energy Labrotaory (NREL).

Note 12. World Business Council for Sustainable Development, 2015. Cement Sustainability Initiative: GNR Project Reporting CO2. Retrieved from http://www.wbcsdcement.org/GNR-2012/index.html_

Note 13. Note that mass units are converted into metric ton for consistency in the GAMS model.

Note 14. Other references we used for the model parameters on cement production process are Olsen et al. (2010), Portland Cement Association (PCA) reports, U.S. Geological Survey Cement reports and discussions with engineers affiliated with PCA.

\section{Appendix}

Table A1. Model parameters for non-multi period inputs requirements

\begin{tabular}{|c|c|c|c|}
\hline Inputs & Required Amount & Unit Price & Production Activity \\
\hline Limestone & 0.87640 metric ton & $\$ 105.23 /$ metric ton & RAW \\
\hline Clay & 0.00864 metric ton & $\$ 10.88 /$ metric ton & RAW \\
\hline Other & 0.07683 metric ton & $\$ 0.01 /$ metric ton & RAW \\
\hline Water & 0.023 gallons & $\$ 1.50 /$ gallons & RAW \\
\hline Gypsum & 0.06146 metric ton & $\$ 9 /$ metric ton & CEM-1 \\
\hline Coal & 0.06866 metric ton & $\$ 27.12 /$ metric ton & KILN \\
\hline Fuel Oil & 0.04 gallons & $\$ 2.96 /$ gallons & KILN \\
\hline
\end{tabular}

Table A2. Summary of optimal solutions by finish grinding capacity for illinois winter electricity price states of nature

\begin{tabular}{cccccc}
\hline $\begin{array}{c}\text { Finish Grinding } \\
\text { Capacity }\end{array}$ & $\begin{array}{c}\text { Electricity } \\
\text { Price State of Nature }\end{array}$ & Net Revenue & $\begin{array}{c}\text { Cement Production } \\
\text { MT }\end{array}$ & $\begin{array}{c}\text { Finish Grinding } \\
\text { Delay, Hours }\end{array}$ & $\begin{array}{c}\text { Average Electricity } \\
\text { Price Paid, cents/KWH }\end{array}$ \\
\hline $100 \%$ & $2015-2016$ & $\$ 1,257,445$ & 36,414 & 0.1 & 2.27 \\
& $2016-2017$ & $\$ 1,241,024$ & 36,414 & 0.1 & 9.1 \\
\hline
\end{tabular}




\begin{tabular}{|c|c|c|c|c|c|}
\hline & & \multicolumn{4}{|c|}{ - Expected Values ${ }^{*}$} \\
\hline \multirow{4}{*}{$105 \%$} & & $\$ 1,243,940$ & 36,388 & 3.1 & 2.49 \\
\hline & 2015-2016 & $\$ 1,260,596$ & 36,414 & 203.5 & 2.22 \\
\hline & 2016-2017 & $\$ 1,244,269$ & 36,414 & 203.5 & 2.49 \\
\hline & 2017-2018 & $\$ 1,239,032$ & 36,414 & 203.5 & 2.59 \\
\hline & & $\$ 1,247,966$ & 36,414 & $\begin{array}{c}\text { d Values } \\
203.5\end{array}$ & 2.43 \\
\hline \multirow[t]{5}{*}{$110 \%$} & 2015-2016 & $\$ 1,261,385$ & 36,414 & 388.4 & 2.20 \\
\hline & 2016-2017 & $\$ 1,245,140$ & 36,414 & 388.4 & 2.48 \\
\hline & $2017-2018$ & $\$ 1,240,152$ & 36,414 & 388.4 & 2.57 \\
\hline & & \multicolumn{4}{|c|}{-Expected Values ${ }^{*}$} \\
\hline & & $\$ 1,248,892$ & 36,414 & 388.4 & 2.42 \\
\hline \multirow[t]{5}{*}{$115 \%$} & 2015-2016 & $\$ 1,261,878$ & 36,414 & 557.3 & 2.19 \\
\hline & 2016-2017 & $\$ 1,245,717$ & 36,414 & 557.3 & 2.47 \\
\hline & 2017-2018 & $\$ 1,240,893$ & 36,414 & 557.3 & 2.56 \\
\hline & & \multicolumn{4}{|c|}{-Expected Values ${ }^{*}$} \\
\hline & & $\$ 1,249,496$ & 36,414 & 557.3 & 2.41 \\
\hline
\end{tabular}

Note. Price states of nature are assumed to be equally likely, so the probability of each state is $1 / 3$.

Table A3. Summary of optimal solutions by finish grinding capacity for illinois summer electricity price states of nature

\begin{tabular}{|c|c|c|c|c|c|}
\hline $\begin{array}{c}\text { Finish Grinding } \\
\text { Capacity }\end{array}$ & $\begin{array}{c}\text { Electricity } \\
\text { Price State of Nature }\end{array}$ & Net Revenue & $\begin{array}{c}\text { Cement Production } \\
\text { MT } \\
\end{array}$ & $\begin{array}{c}\text { Finish Grinding } \\
\text { Delay, Hours }\end{array}$ & $\begin{array}{c}\text { Average Electricity } \\
\text { Price Paid, cents/KWH }\end{array}$ \\
\hline \multirow[t]{4}{*}{$100 \%$} & $2015-2016$ & $\$ 1,250,184$ & 37,232 & 0.1 & 2.87 \\
\hline & 2016-2017 & $\$ 1,255,974$ & 37,156 & 9.1 & 2.72 \\
\hline & $2017-2018$ & $\$ 1,252,261$ & 37,232 & 0.1 & 2.83 \\
\hline & & $\$ 1,252,806$ & 37,207 & $\begin{array}{c}\text { xpected Values }^{*}- \\
3.1\end{array}$ & 2.81 \\
\hline \multirow[t]{4}{*}{$105 \%$} & $2015-2016$ & $\$ 1,257,145$ & 37,232 & 208.1 & 2.75 \\
\hline & $2016-2017$ & $\$ 1,262,549$ & 37,232 & 208.1 & 2.65 \\
\hline & $2017-2018$ & $\$ 1,257,598$ & 37,232 & 208.1 & 2.74 \\
\hline & & $\$ 1,259,097$ & 37,232 & $\begin{array}{c}\text { pected Values }{ }^{*} \text { - } \\
208.1\end{array}$ & 2.71 \\
\hline \multirow[t]{4}{*}{$110 \%$} & $2015-2016$ & $\$ 1,258,868$ & 37,232 & 397.1 & 2.72 \\
\hline & $2016-2017$ & $\$ 1,263,811$ & 37,232 & 397.1 & 2.63 \\
\hline & $2017-2018$ & $\$ 1,259,097$ & 37,232 & 397.1 & 2.72 \\
\hline & & $\$ 1.260 .592$ & 37.232 & $\begin{array}{c}\text { pected Values }{ }^{*} \text { - } \\
397.1\end{array}$ & 2.69 \\
\hline \multirow[t]{4}{*}{$115 \%$} & $2015-2016$ & $\$ 1,259,914$ & 37,232 & 569.8 & 2.71 \\
\hline & $2016-2017$ & $\$ 1,264,699$ & 37,232 & 569.8 & 2.62 \\
\hline & $2017-2018$ & $\$ 1,260,084$ & 37,232 & 569.8 & 2.7 \\
\hline & & $\$ 1,261,566$ & 37,232 & $\begin{array}{c}\text { pected Values }{ }^{*} \\
569.8\end{array}$ & 2.68 \\
\hline
\end{tabular}

Note. Price states of nature are assumed to be equally likely, so the probability of each state is $1 / 3$.

Table A4. Summary of optimal solutions by finish grinding capacity for michigan winter electricity price states of nature

\begin{tabular}{|c|c|c|c|c|c|}
\hline $\begin{array}{c}\text { Finish Grinding } \\
\text { Capacity }\end{array}$ & $\begin{array}{c}\text { Electricity } \\
\text { Price State of Nature }\end{array}$ & Net Revenue & $\begin{array}{c}\text { Cement Production } \\
\text { MT }\end{array}$ & $\begin{array}{c}\text { Finish Grinding } \\
\text { Delay, Hours }\end{array}$ & $\begin{array}{c}\text { Average Electricity } \\
\text { Price Paid, cents/KWH }\end{array}$ \\
\hline \multirow[t]{4}{*}{$100 \%$} & $2015-2016$ & $\$ 1,258,714$ & 36,414 & 0.1 & 2.24 \\
\hline & 2016-2017 & $\$ 1,228,954$ & 36,414 & 0.1 & 2.76 \\
\hline & $2017-2018$ & $\$ 1,211,120$ & 36,337 & 9.1 & 3.03 \\
\hline & & $\$ 1,232,929$ & 36,388 & $\begin{array}{c}\text { ected Values }{ }^{*} \\
3.1\end{array}$ & 2.68 \\
\hline \multirow[t]{3}{*}{$105 \%$} & $2015-2016$ & $\$ 1,260,913$ & 36,414 & 203.5 & 2.2 \\
\hline & 2016-2017 & $\$ 1,232,546$ & 36,414 & 203.5 & 2.7 \\
\hline & $2017-2018$ & $\$ 1,218,020$ & 36,414 & 203.5 & 2.95 \\
\hline
\end{tabular}




\begin{tabular}{|c|c|c|c|c|c|}
\hline & & 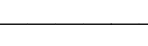 & 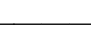 & d Values & \\
\hline & & $\$ 1,237,160$ & 36,414 & 203.5 & 2.62 \\
\hline \multirow[t]{5}{*}{$110 \%$} & $2015-2016$ & $\$ 1,261,461$ & 36,414 & 388.4 & 2.19 \\
\hline & 2016-2017 & $\$ 1,233,423$ & 36,414 & 388.4 & 2.68 \\
\hline & $2017-2018$ & $\$ 1,219,231$ & 36,414 & 388.4 & 2.93 \\
\hline & & & $x_{0}+2$ & d Values & \\
\hline & & $\$ 1,238,038$ & 36,414 & 388.4 & 2.60 \\
\hline \multirow[t]{4}{*}{$115 \%$} & 2015-2016 & $\$ 1,261,838$ & 36,414 & 557.3 & 2.19 \\
\hline & 2016-2017 & $\$ 1,234,021$ & 36,414 & 557.3 & 2.67 \\
\hline & 2017-2018 & $\$ 1,219,964$ & 36,414 & 557.3 & 2.92 \\
\hline & & $\$ 102060$ & 2644 & d Values & 500 \\
\hline
\end{tabular}

Note. Price states of nature are assumed to be equally likely, so the probability of each state is $1 / 3$.

Table A5. Summary of optimal solutions by finish grinding capacity for michigan summer electricity price states of nature

\begin{tabular}{|c|c|c|c|c|c|}
\hline $\begin{array}{c}\text { Finish Grinding } \\
\text { Capacity } \\
\end{array}$ & $\begin{array}{c}\text { Electricity } \\
\text { Price State of Nature }\end{array}$ & Net Revenue & $\begin{array}{c}\text { Cement Production } \\
\text { MT } \\
\end{array}$ & $\begin{array}{c}\text { Finish Grinding } \\
\text { Delay, Hours } \\
\end{array}$ & $\begin{array}{c}\text { Average Electricity } \\
\text { Price Paid, cents/KWH }\end{array}$ \\
\hline \multirow[t]{4}{*}{$100 \%$} & $2015-2016$ & $\$ 1,232,197$ & 37,156 & 9.1 & 3.13 \\
\hline & $2016-2017$ & $\$ 1,247,380$ & 37,156 & 9.1 & 2.87 \\
\hline & $2017-2018$ & $\$ 1,241,097$ & 37,232 & 0.1 & 3.02 \\
\hline & & $\$ 1,240,225$ & 37,181 & $\begin{array}{c}\text { pected Values }{ }^{*}- \\
6.1\end{array}$ & 3.01 \\
\hline \multirow[t]{4}{*}{$105 \%$} & $2015-2016$ & $\$ 1,241,063$ & 37,232 & 208.1 & 3.03 \\
\hline & $2016-2017$ & $\$ 1,254,135$ & 37,232 & 208.1 & 2.80 \\
\hline & $2017-2018$ & $\$ 1,247,389$ & 37,232 & 208.1 & 2.92 \\
\hline & & $\$ 1,247,529$ & 37,232 & $\begin{array}{c}\text { pected Values* } \\
208.1\end{array}$ & 2.92 \\
\hline \multirow[t]{5}{*}{$110 \%$} & $2015-2016$ & $\$ 1,243,202$ & 37,232 & 397.1 & 2.99 \\
\hline & $2016-2017$ & $\$ 1,255,600$ & 37,232 & 397.1 & 2.78 \\
\hline & $2017-2018$ & $\$ 1,249,120$ & 37,232 & 397.1 & 2.89 \\
\hline & & & & ected Values ${ }^{*}$ & \\
\hline & & $\$ 1,249,308$ & 37,232 & 397.1 & 2.89 \\
\hline \multirow[t]{5}{*}{$115 \%$} & $2015-2016$ & $\$ 1,244,554$ & 37,232 & 569.8 & 2.97 \\
\hline & $2016-2017$ & $\$ 1,256,572$ & 37,232 & 569.8 & 2.76 \\
\hline & $2017-2018$ & $\$ 1,250,181$ & 37,232 & 569.8 & 2.87 \\
\hline & & & 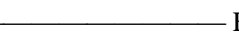 & cted Values* & \\
\hline & & $\$ 1,250,436$ & 37,232 & 569.8 & 2.87 \\
\hline
\end{tabular}

Note. Price states of nature are assumed to be equally likely, so the probability of each state is $1 / 3$.

\section{Copyrights}

Copyright for this article is retained by the author(s), with first publication rights granted to the journal.

This is an open-access article distributed under the terms and conditions of the Creative Commons Attribution license (http://creativecommons.org/licenses/by/4.0/). 